\title{
ATUAÇÃO EM CLASSES MULTISSERIADAS EM UMA ESCOLA DO CAMPO E A PARCERIA COMUNITÁRIA
}

\author{
Andrieli Alves da Cruz Santin D1, Cristina Ide Fujinaga (D2, Elaine Cristina de \\ Oliveira 3
}

Resumo: O presente estudo tem como objetivo discorrer sobre as práticas pedagógicas de uma escola do campo com organização multisseriada, a formação das professoras e como ocorre o desenvolvimento no ensinoaprendizagem. A pesquisa tem ênfase no foco qualitativo, pois envolve a representação de um determinado grupo social. E ocorreu em uma escola do campo do interior paranaense, em que o município tem uma porcentagem elevada da população na área rural. Os dados foram coletados através de entrevistas junto às professoras e sistematizados pela análise de conteúdo. Os resultados obtidos demonstram que, embora não se tenha políticas públicas voltadas para a Educação do Campo, assim como os professores não têm uma formação específica para atuar em classes multisseriadas. O processo de ensinoaprendizagem acontece pela dinâmica e protagonismo dos professores juntamente com a comunidade escolar.

Palavras-chave: Educação do Campo; Classes Multisseriadas; Projetos Educacionais; Comunidade Escolar.

\section{PERFORMANCE IN MULTISERIES CLASSES IN A SCHOOL IM CAMPO AND THE COMMUNITY PARTNERSHIP}

Abstract: The present study intends to discuss the pedagogical practices of a rural school with a multigrade organization, the training of teachers and how development occurs in teaching and learning. The research has an emphasis on qualitative focus, as it involves the representation of a certain social group. The same occurred in a school in the countryside of Paraná, where the municipality has a high percentage of the population in the rural area. Data were collected through interviews with teachers and systematized by content analysis. The results obtained demonstrate that, although there is no government investment in policies aimed at Rural Education, whether in professional training issues to work in multi-grade classes or in structural issues, the school community is organized so that the teaching-learning process happens, both for the dynamics

\footnotetext{
${ }^{1}$ Mestra em Desenvolvimento Comunitário pela Universidade Estadual do Centro-Oeste do Paraná (UNICENTRO). Professora nos anos iniciais na Educação do Campo. E-mail: cruzandrieli@gmail.com.

${ }^{2}$ Doutora Enfermagem em Saúde Pública pela Escola de Enfermagem da Universidade de São Paulo (USP/Ribeirão Preto). Professora Associada do Departamento de Fonoaudiologia da Universidade Estadual do Centro-Oeste do Paraná (UNICENTRO). E-mail: cifujinaga@gmail.com. 3Doutora em Linguística pela Universidade Estadual de Campinas (UNICAMP). Professora Associada II da Universidade Federal da Bahia (UFBA), vinculada ao Departamento de Fonoaudiologia. E-mail: elaineoliveira1009@gmail.com.
} 
and protagonism of the teachers, as well as for the actions carried out together with the school community.

Keywords: Education; Multigrade Classes; Educational Projects;School Community.

\section{Introdução}

A educação brasileira vem de um processo histórico que deu prioridade às demandas do contexto urbano, especificamente ao regime seriado. Mesmo sendo um país considerado agrário, as escolas do campo só aparecem em leis devido à manifestação de grupos sociais do campo que lutam para que as escolas permaneçam em suas comunidades e, ainda, para que a educação seja realmente voltada ao povo camponês.

Ao se mencionar em escolas multisseriadas, vale apena destacar que este termo é desconhecido por muitos, ou considerado algo que existiu há muitos anos, porém faz parte de um contexto atual. A multisseriação acontece com crianças de várias idades que frequentam uma mesma sala de aula, com apenas um docente. São séries/idades diferentes estudando num mesmo local

De acordo com dados coletados por Pianovski (2017), o total de turmas multietapas e multisseriadas, em 2015, no Brasil, correspondia a 86.448 turmas, e no Paraná havia 592 turmas. Mesmo aparecendo em dados estatísticos, muitos professores que atuam nessas escolas não recebem a formação nos cursos de graduação, pois pouco se fala da Educação do Campo e das classes multisseriadas.

Muitas escolas do campo foram nuclearizadas, quer dizer, fechou-se as escolas menores, e os alunos foram enviados a outras escolas próximas de sua comunidade, com uma melhor estrutura para que pudessem estudar em classes seriadas, correspondente a sua faixa etária. Muitas escolas do campo foram nuclearizadas, isto é, fecharam-se as escolas menores e os alunos foram enviados a outras escolas, próximas de sua comunidade, com uma melhor estrutura para que pudessem estudar em classes seriadas, correspondente a sua faixa etária. Uma das justificativas para o fechamento das escolas multisseriadas é a heterogeneidade do ambiente escolar, considerada como um fator que dificulta (ou impede) o trabalho pedagógico do professor. Já os estudos de HAGE (2014) salientam que:

Contudo, os fundamentos teóricos que orientam nossos estudos apontam justamente o contrário, indicando ser a heterogeneidade um elemento potencializador da aprendizagem e enriquecedor do ambiente escolar, que poderia ser melhor aproveitado na experiência educativa que se efetiva nas escolas rurais multisseriadas, carecendo, no entanto, de mais estudos e investigações sobre a organização do trabalho pedagógico, o planejamento e a construção do currículo, sintonizados com as peculiaridades de vida e de trabalho das populações do campo, o que de forma nenhuma, em nosso entendimento, significa a perpetuação da experiência precarizada de educação que se efetiva nas escolas rurais multisseriadas tal qual refletimos nesse artigo (Hage, 2014, p. 1180) 
Porém existe uma parcela da população que luta para que a escola do campo seja valorizada e permaneça na comunidade, pois a escola é vista pela comunidade como um espaço de significações, e muitas são as comunidades que lutam para manter a escola no campo, além de lutar para que a educação seja voltada ao povo camponês.

O objetivo desta pesquisa é mostrar a formação dos professores do campo, mais especificamente os que trabalham em classes multisseriadas, bem como apresentar a experiência de aprendizagens inovadoras, que acontecem através de projetos desenvolvidos pela comunidade escolar, relatando a vivência do campo.

\section{Metodologia}

Para que o presente estudo se constituísse, optou-se pela pesquisa qualitativa, pois de acordo com Minayo (2010): "se aplica ao estudo das relações, das representações, das crenças, das percepções e opiniões, produtos das interpretações que os humanos fazem a respeito de como vivem." (Minayo, 2010, p. 57).

Como instrumento de coleta de dados, foram realizadas entrevistas com as professoras, com perguntas semiestruturadas, as quais foram gravadas e depois transcritas. O relato das professoras permitiu conhecer um pouco da trajetória educacional nas escolas do campo, as metodologias utilizadas nas classes multisseriadas. No presente estudo, descreveu-se o projeto realizado pela escola com o resgate das plantas medicinais.

Utilizou-se da análise de conteúdo para interpretar os dados obtidos, direcionando o resultado por unidades temáticas. Minayo (2010) propõe que a análise de conteúdo seja realizada pela organização de eixos que surgem durante a pesquisa. Analisar as temáticas requer encontrar um núcleo com sentidos em comum, o que está estreitamente ligado ao objeto pesquisado.

\section{Resultados e discussões}

\subsection{A formação de professores da escola do campo}

As classes multisseriadas são desconhecidas por muitos dos educadores, mesmo sendo pesquisada uma região onde existem muitas escolas do campo com organização multisseriada, muitos professores chegam até as escolas sem uma formação específica. Pois muitas são as universidades que não oferecem a formação para a Educação do Campo, muito menos em relação às classes multisseriadas.

Little (2004) enfatiza em seus estudos que: "a maioria dos sistemas de treinamento de professores antes e durante o serviço prepara os professores para ensinar em escolas monogradas". Ela se refere monogradas a seriadas, ou seja, a formação que ocorre é em relação às classes seriadas.

As professoras pesquisadas serão referenciadas nesse estudo como $\mathrm{N} 1$, Z2 e M3. A professora N1, possui 35 anos, atua como professora há doze anos, sendo sete em instituição privada e seis anos na escola do campo com 
organização em classes multisseriadas. A professora Z2, tem 37 anos e atua como professora há oito anos, sempre na escola do campo, porém, por um ano atuou em escola seriada, após ser transferida para outra escola com organização multisseriada. A professora M3, tem 43 anos, atua há cinco anos como professora e desde que assumiu o concurso leciona em classes multisseriadas. As três possuem formação no curso de graduação em Pedagogia, por duas instituições universitárias distintas, sendo uma privada e outra pública, a professora M3 cursou o magistério e passados alguns anos fez sua graduação em EAD, as professoras N1 e Z2 não cursaram o magistério e fizeram sua graduação em uma universidade pública, de forma presencial. Porém em nenhuma delas foi referenciado as classes multisseriadas. Ao serem indagadas sobre à formação para trabalhar em classes multisseriadas, obteve-se as seguintes respostas:

Na graduação é, eu não tive nenhuma formação específica, que abordasse o tema, ou que fosse direcionado à escola do campo, muito menos a classe multisseriada. A gente, quando assume o concurso, a gente assume a vaga que tem, e cai de paraquedas lá numa escola do campo, onde todo mundo estudava na mesma turma, né. É difícil? É. Você não tem uma formação específica para isso [...] (Professora N1).

Não, não tive formação para atuar em classes multisseriadas. Até quando comecei, me assustei bastante, porque eu peguei turma de 30,40 e $5^{\circ}$ ano, que não era uma realidade do que tinham passado para nós na faculdade, né! O que passavam para nós é do que seria seriada... e quando eu comecei, e vim pra cá na multisseriada, foi um susto grande. Porque pegar $3^{\circ}, 4^{\circ}$ e $5^{\circ}$ tudo junto. Tem os estágios, mas os estágios é ...foi baseado em escolas seriadas, não foi passado que teria multisseriada ainda que existia a multisseriada" (Professora Z2).

Não tive nenhuma formação para trabalhar em classe multisseriada. $\mathrm{Na}$ verdade, nem tivemos no curso de Pedagogia sobre classes multisseriadas. A gente nem estudou e nem teve essa formação (Professora M3).

Parente (2014) também compartilha da visão de que os professores, na maioria das vezes, não têm formação de como atuar nas classes multisseriadas. Visão esta que ficou clara na fala das professoras.

O documento "A Handbook for Teachers of Multi-Grade Classes" (Um Manual para Professores de Classes Multisseriadas), redigido pela UNESCO em 2001, expõe sobre a formação do professor: "As habilidades necessárias para gerenciar os alunos e ensinar em um ambiente de várias séries, geralmente não são ensinados em faculdades de treinamento." (2001, p. 21).

A formação de professores para atuar em classes multisseriadas é algo que, geralmente, muitas universidades não oferecem, e os professores que, como a professora N1 relatou, "caem de paraquedas" nas escolas multisseriadas, devem se adaptar a essa realidade escolar.

As Diretrizes Curriculares da Educação do Campo do Paraná, 2010, trazem em seu texto sobre a falta de formação de professores para atuar na Educação do Campo: 


\begin{abstract}
Hoje, os professores saem dos bancos escolares, dos cursos de licenciatura, sem ter estabelecido qualquer discussão sobre o modo de vida camponês, pressupondo que o modo de vida urbano prevalece em todas as relações sociais e econômicas brasileiras. Da mesma forma, a maioria dos cursos de formação continuada deixa de valorizar a educação do campo (SEED, 2010, p.33).
\end{abstract}

Além da formação, Caldart (2008) relata que os princípios fundamentais para a formação de professores que atuam em escolas/classes multisseriadas do campo, precisam articular-se com a Educação do Campo. Se faz necessário inserir uma educação que seja voltada à realidade do campo, com as experiências cotidianas. Para que isso se efetive, é necessário a elaboração de políticas públicas em favor do povo do campo, e que essas se efetivem e não fiquem somente como uma política assistencialista ao indivíduo que reside no meio rural.

$\mathrm{Na}$ entrevista, as professoras relatam que a formação que tiveram foi a partir do Programa Escola da Terra. Esse programa teve início em 2012 e foi implementado em estados brasileiros sob a coordenação da Secretaria de Educação Continuada, Alfabetização, Diversidade e Inclusão (SECADI) do Ministério da Educação (MEC) em parceria com municípios e sete universidades públicas federais: a Universidade Federal de Minas Gerais (UFMG), a Universidade Federal da Bahia (UFBA), a Universidade Federal do Rio Grande do Sul (UFRGS), a Universidade Federal do Maranhão (UFMA), a Universidade Federal do Amazonas (UFAM), a Universidade Federal do Pará (UFPA) e a Universidade Federal de Pernambuco (UFPE).

No Paraná, o Programa Escola da Terra foi coordenado pela Universidade Federal Fronteira Sul (UFFS) com parceria da Universidade Estadual do CentroOeste (UNICENTRO), de Guarapuava, com a formação em três polos, que compreendeu as cidades de Cândido de Abreu e Prudentópolis, bem como o Movimento dos Trabalhadores Rurais Sem Terra (MST), nos anos de 2016 e 2017.

O Programa Escola da Terra prevê a formação continuada dos professores com cursos de aperfeiçoamento, equipe local responsável pelo acompanhamento pedagógico e disponibilização de conjunto de materiais pedagógicos específicos. Este programa objetiva contemplar as classes multisseriadas do campo com ações voltadas à promoção da qualidade do ensino nas escolas do campo (MEC, 2012).

Ao criar-se o Programa Escola da Terra, no que diz respeito à formação dos professores, o SECADI/MEC inclui que:

A preparação, formação dos educadores, dos formadores, para além da técnica de ensino e da gestão restrita, que acabam secundarizando as demais dimensões do ato de ensinar e aprender, como são as dimensões do pensamento e atitude científica, política, técnica, ética, moral, estética. As reivindicações dos professores do campo, no que diz respeito às responsabilidades do Governo Federal, Estadual, Municipal e da Universidade para garantir efetivamente a implementação de diretrizes da Educação do Campo nas escolas multisseriadas, devem ser asseguradas (SECADI/MEC, 2012). 
Assim, a formação que as professoras tiveram em 2016 e 2017 para atuar em classes multisseriadas foi com a proposta de trabalho elencado pelo Programa Escola da Terra. Tal proposta contribuiu para que as aulas em classes multisseriadas acontecessem de forma favorável com a realidade dos educandos.

No ano de 2016 e 2017, que teve a formação, era o nome do curso era Escola da Terra, uma formação é, se não me engano, pela Universidade Fronteira Sul, aí nós pudemos nos sentar, ler, conversar, debater assuntos direcionados as escolas do campo e as classes multisseriadas. Aí todas as professoras que trabalhavam nas escolas do campo podiam se reunir para trocar experiência (Professora N1).

Foi mesmo o Projeto Escola da Terra que deu uma base para trabalhar na escola do campo (Professora Z2).

Tivemos a formação da Escola da Terra, que foi uma formação muito interessante (Professora M3).

Fontana, Rocha e Dambrat (2018) enfatizam em seus estudos que o processo de formação continuada contribuiu para o acesso e compreensão dos direitos legais que regem a Educação do Campo e de conteúdos relativos à vida, cultura e trabalho no campo, os quais favoreceram a construção e materialização do projeto político-pedagógico emancipador.

3.2 Metodologias utilizadas nas classes multisseriadas e o desenvolvimento do ensino aprendizagem.

Pelo fato de não conhecer e não ter uma formação voltada à realidade das escolas multisseriadas, muitas vezes a ausência de orientação leva o professor a reproduzir o modelo de ensino seriado, mesmo tendo mais de uma turma em sala, o que ocasiona trabalhos duplicados para o professor, e até mesmo, quintuplicados; tendo em conta que são alunos de várias turmas, assim como evidencia Parente (2014). As professoras relatam que:

No início, eu segui mais ou menos a linha da professora que estava no ano anterior. Ela dividia o quadro, né, em alguns assuntos, né, é, $1^{\circ}$ ano, $2^{\circ}, 3^{\circ}$ e $4 \circ$ e tinha atividades que dava para realizar com todos os alunos (Professora N1).

É bem puxado, no começo eu tentei dividir o quadro, $3^{\circ}, 4^{\circ}$ e $5 \circ$, mas não deu muito certo. Porque umas até conseguiam acompanhar, outras não, misturavam conteúdos, não deu muito certo, daí depois tive que ir adaptando conteúdos que desse certo para os três, para as três turmas. Daí trabalhava o mesmo conteúdo, de forma diferenciada (Professora Z2).

Parente (2014) relata também que um dos currículos existentes nas escolas multisseriadas é o modelo de currículo diferenciado, uma versão do currículo quase monograduado. 
Neste modelo, há um tema geral tratado do começo ao fim das atividades com todos os alunos. Entre um momento e outro, são fornecidas atividades diferenciadas, com base de níveis de aprendizagem e/ou habilidade e com objetivos específicos, as quais são realizadas em grupo e durante as quais professor fornece pequenas explicações aos subgrupos (PARENTE, 2014, p. 67).

Modelo este que se assemelha às falas das professoras entrevistadas, as quais buscam trabalhar um mesmo conteúdo com todos, mas, em alguns momentos, com atividades com níveis diferenciados. A professora relata que:

\begin{abstract}
Em alguns momentos, a atividade é feita diferenciada para eles, é, mas muitas vezes a mesma avaliação, se o conteúdo, foi dado para a turma, se a turma estava na mesma sala durante a aula, se era o mesmo conteúdo, eu não vejo a necessidade de fazer outra avaliação. Fazia a mesma avaliação, e as vezes, com grau de dificuldade mais acentuada para os maiores, mas em si a avaliação era a mesma para as duas turmas, no caso da nossa escola, que é bisseriada (Professora N1).
\end{abstract}

Parente (2014) ainda fala que existe a ausência de critérios na organização das turmas multisseriadas, para além da seriação. Há um desejo de que a multisseriação avance para um olhar mais atento aos sujeitos da educação e, inclusive, elimine o fardo nominal que carrega, estreitamente articulado à seriação.

Entretanto, os dados realizados na pesquisa mostram que o professor da classe multisseriada se sobrecarrega para atingir os objetivos elencados pela Base Nacional Curricular Comum, os quais são desenvolvidos para as classes seriadas. Ainda falta políticas públicas que realmente sejam efetivadas para a Educação do Campo.

Entre as falas, também se observam relatos sobre o material didático ofertado para as escolas do campo, os quais vêm deslocados de sua realidade.

No começo quando a gente começou aqui na escola, não tinha material, [...] daí depois veio material para o 10, 30, mas era um material deslocado da realidade né... era um material muito diferente da realidade daqui (Professora Z2).

Segundo uma das orientações do MEC, os materiais didáticos devem ser criados em consonância com os princípios pedagógicos e, consequentemente, de acordo com o referencial teórico que o sustenta (BRASIL, 2015).

Porém os estudos realizados por Caldart (2004), Oliveira (2012) e Taffarel (2016) salientam a desvalorização dos materiais enviados às escolas do campo, os quais são deslocados de sua realidade educacional. Sabe-se que o livro didático é um dos meios para a aprendizagem, porém em muitas escolas do campo, a falta de recursos de materiais pedagógicos prevalece, e uma das alternativas é o uso do livro que chega à escola, mas que não condiz com a realidade camponesa.

Conforme os estudos realizados por Oliveira (2012), o trabalho docente não atende à diversidade de realidades sociais encontradas no campo, tampouco existem materiais didáticos voltados para essas múltiplas realidades. Caldart 
(2008) ressalta que se faz necessário no campo brasileiro o alargamento da função social da escola e da superação de currículos pobres, assépticos, sem vida social, cultural, política.

Taffarel (2016) também compartilha da ideia de que se enfrenta um processo de desqualificação de formação, constatável nos seguintes aspectos:

a) da negação do conhecimento científico como base imprescindível para a consciente explicação e ação na realidade; b) da marginalização da referência teórica de base materialista histórica e dialética nos currículos; c) da avaliação controlada ideologicamente; d) do silenciamento das leis que regem o modo de produção capitalista, a luta de classes e o Estado burguês; e) da criminalização dos movimentos de luta social e das organizações sindicais da classe trabalhadora; f) da ausência de referência ao projeto histórico de superação da sociedade de classes, o projeto histórico socialista (TAFFAREL, 2016, p. 431).

Porém, o que ainda permanece nas escolas do campo são materiais didáticos que não correspondem à realidade do povo do campo. Crítica essa voltada também a um dos programas oferecidos pelo governo federal para as escolas do campo, o Programa Escola Ativa, o qual iniciou em 1997, na região nordeste e se efetivou em todo território brasileiro. Tal programa apresentava conteúdo fora da realidade do povo do campo, não se preocupando com os anseios do homem camponês.

O principal enfrentamento para os professores é o compromisso com o ensino-aprendizagem. Caldart (2003) explica que precisa ter tempo, organização e formação pedagógica, para que a escola seja realmente um espaço educativo, criando e recriando estratégias para a formação humana e as relações sociais; e assim, efetivar o processo de ensino-aprendizagem.

Quanto ao desenvolvimento $\operatorname{dos}(a s)$ alunos(as), as professoras entrevistadas relatam que:

Por incrível que pareça é gratificante você vê, né, a evolução deles, por independente deles está numa mesma sala de aula, eles estarem em séries diferentes, ter idades diferentes, o desenvolvimento acontece, porque um vai ajudando o outro na realização das atividades, é, numa leitura, é, um vai tomando a tabuada do outro, outro vai ajudando a fazer uma conta, então eles vão se ajudando né, um vai auxiliando outro, né, e ocorre o processo de aprendizagem aí (Professora $1 \mathrm{~N}$ ).

Depois que comecei a trabalhar o mesmo conteúdo com todos, foi mais fácil, né. Um ia ajudando o outro e via que eles aprendiam. Um ajudando o outro e ajudando a professora junto. (risos) (Professora Z2).

Prestes (2010, p.168) evidencia em seus estudos que a zona de desenvolvimento iminente, descrita por Vigotski, "está intimamente ligada à relação existente entre desenvolvimento e instrução e a ação colaborativa de outra pessoa". A autora relata também que "Vigotski não diz que a instrução é garantia de desenvolvimento, mas que ela, ao ser realizada em uma ação colaborativa, seja do adulto ou entre pares, cria possibilidades para o desenvolvimento". 
Diante dessas considerações apontadas por Prestes (2010), pode-se dizer que o desenvolvimento dos alunos(as) das classes multisseriadas acontece pela ajuda colaborativa entre professor e aluno, como também entre aluno e aluno.

As professoras relatam também que a partir do momento que passaram a desenvolver projetos de acordo com a realidade da comunidade, ressaltando seu dia a dia com os conteúdos, a aprendizagem passou a se efetivar de maneira que despertou 0 interesse dos alunos em querer saber mais da vida comunitária.

Assim, através dos projetos, pode-se notar que não foram deixados de lado o contexto histórico da criança, a qual relata o seu dia; e essa é também uma forma de viabilizar a aprendizagem.

\subsection{O Resgate das plantas medicinais}

Um dos projetos realizados pelas professoras foi em relação ao resgate das plantas medicinais, o qual veio ao encontro da formação que tiveram com o Programa Escola da Terra. O projeto foi desenvolvido por toda a comunidade escolar, no ano de 2014, e permanece até hoje fazendo parte da vida escolar, tanto para o ensino-aprendizagem dos alunos como para a comunidade.

Num primeiro momento, os pais foram convocados para uma reunião escolar, e as professoras explanaram sobre o projeto, sobre como ocorreria. Os pais aceitaram participar e colaborar para que se chegasse ao empreendimento da melhor forma possível.

O Projeto Resgate das Plantas Medicinais, surgiu na formação Escola da Terra, no intuito de mostrar o que há no campo, e sabe-se que no meio rural é comum remediar através das plantas medicinais, que servem como tratamento de muitas doenças, as professoras relatam como ocorreu tal projeto:

No projeto das plantas medicinais, foram os pais que vieram até a escola para ajudar na confecção (construção) dos canteiros, né, para puxar a terra. As mães que trouxeram as mudas, trouxeram adubo, e vieram plantar, para resgatar mesmo, né, as plantinhas que estavam esquecidas lá nas suas casas. Muitas não sabiam nem o que que era o benefício daquela planta né, e trouxeram para a escola, resgatando as plantas e falando para que são usadas, tanto para medicalizar, quanto para os temperos utilizados na merenda das crianças (Professora $1 \mathrm{~N}$ ).

Outra professora complementa dizendo:

Teve a troca das plantas medicinais, a mãe que não tinha aquele tipo de plantinha, levava para a casa, foi bem interessante esse projeto. Foi uma troca de experiência. E nessa troca de experiência envolveu toda a comunidade escolar, assim como os aluno (Professora 3M).

Em relação ao projeto desenvolvido na escola, nota-se o apoio da comunidade escolar. Brito (2000) salienta em seus estudos, que a participação é um processo que pode ser concebido como instrumento, ou seja, a população demonstra interesse e precisa se organizar em prol de seus interesses, assim como a participação pode ser também um fim, pois representa a satisfação dos 
interesses da maioria. Se remetermos à história, Aristóteles já falava em seus discursos que a participação é um fator central da democracia e até mesmo da existência humana. Assim como Rousseau, o qual evidencia que a participação tinha efeitos educativos para a sociedade e trazia efeitos positivos individualmente e coletivamente (MARCONDES, 2008).

No projeto, houve o envolvimento dos pais na execução do canteiro, na troca das plantas medicinais e de seus benefícios para a saúde; foi uma troca de experiências. Além do envolvimento dos pais, as professoras utilizaram desse projeto para mostrar às crianças, da Educação Infantil ao Ensino Fundamental I, o quanto são importantes as plantas medicinais, trabalhando de uma forma interdisciplinar sem deixar de lado os conteúdos propostos pela Base Nacional Curricular Comum - BNCC, para cada etapa de ensino e relacionando com o dia a dia das crianças e comunidade.

Quanto às atividades pedagógicas, relacionadas ao projeto das plantas medicinais, as professoras relatam que:

Foram desenvolvidas várias atividades com as crianças, como a horta e o jardim, os benefícios que as plantas medicinais têm. Para trabalhar com as crianças foi realizado a confecção de jogos, como jogo da memória e dominó com a foto das plantas conhecidas pelos alunos. Eles também realizaram o plantio das plantas medicinais, como também de algumas hortaliças, tanto nos canteiros da escola, como levaram algumas mudas para a casa, para mostrar o trabalho realizado na escola (Professora $1 \mathrm{~N}$ ).

Foi feito também o alfabeto das plantas medicinais, cada letra uma planta diferente. As crianças da Educação Infantil e $1^{\circ}$ e $2^{\circ}$ ano do Ensino Fundamental trouxeram as mudas medicinais e também ajudaram a plantar. Os alunos do $3^{\circ}$ ano confeccionaram um livro, explicando para o que cada planta é utilizada, as crianças usaram a criatividade para a confecção dos livros, os quais ficaram bem bonitos. Já o $4^{\circ}$ e $5^{\circ}$ ano realizaram a confecção de um cartaz explicando sobre as plantas medicinais e interpretando textos relacionados ao assunto (Professora 2Z).

Outra professora lembra:

Também foi realizado uma paródia, a partir da música 'além do horizonte', a qual foi elaborada pelas professoras e cantada por todas as crianças, ficou muito legal paródia, e as crianças sempre estão cantando (Professora 3M).

\section{A professora $\mathrm{P} 1 \mathrm{~N}$ complementa dizendo:}

Foi possível envolver conteúdos diferenciados, nas matérias, como: Português, Matemática, Ciências, História, Geografia, Artes. Foram várias as atividades pedagógicas com um tema que até então, para eles ainda era um pouco desconhecido, que era as plantas medicinais, e que no final pode-se perceber o desenvolvimento educacional das crianças, de acordo com os conteúdos propostos pela Base Nacional Curricular Comum (Professora $1 \mathrm{~N}$ ). 
As professoras buscam, através do resgate das plantas medicinais, envolver os conteúdos de todas as disciplinas, trabalhando de forma interdisciplinar.

Essa intervenção, através de projetos escolares, só é possível quando os profissionais da educação, os quais são os mediadores do processo educativo na escola, desenvolvem uma atitude político-pedagógica para unir o conhecimento particular do campo, a realidade da comunidade, ao conhecimento científico universal.

O projeto desenvolvido na escola vem ao encontro da realidade da comunidade. Caldart (2004) explica que o projeto político-pedagógico deve ser construído com base na concepção de Educação do Campo, pois assim se torna uma possibilidade efetiva de os camponeses assumirem a condição de sujeitos de seu próprio projeto educativo, de aprenderem a pensar o seu trabalho, seu lugar, seu país e sua educação. A autora enfatiza que: "Trata-se de um projeto de educação dos e não para os sujeitos do campo, ou seja, uma possível re (construção) da identidade da escola e dos povos do campo." (2004, p. 28).

Além disso, Souza (2005, p. 29) enfatiza que: "o processo de participação em projetos na escola também produz efeitos culturais importantes. Ele ajuda a comunidade a reconhecer o patrimônio das instituições educativas, como um bem público comum".

Juntos, escola e comunidade, buscam a melhoria na qualidade de vida e do meio em que vivem, sendo que a ação participativa tem oportunizado condições para que alunos, professores e comunidade se sintam motivados a trabalhar em projetos. Além disso, tais ações oportunizam de cumplicidade com propósitos educacionais voltados para o bem-estar de toda a comunidade escolar, além de estimular o sentimento de pertencimento e corresponsabilidade pelo espaço em que vivem.

\section{Considerações finais}

Apesar de as escolas do campo serem vistas por muitos como escolas ultrapassadas ou atrasadas, apesar do fardo nominal que carregam, apesar da ausência de políticas públicas para o povo camponês, a multisseriação vem mostrando na prática pedagógica, que é possível atingir o desenvolvimento do ensino-aprendizagem através de aulas diferenciadas que despertam o interesse dos alunos em aprender e defender a escola do campo, a qual não é uma "escolinha", e sim um espaço com diferentes significações.

Cabe ao professor buscar soluções pedagógicas, que sejam a partir do cotidiano em sala de aula, do fazer-docente, com alternativas pedagógicas diferenciadas, que evidenciem a realidade e história do povo do campo, e assim, buscar a superação das adversidades. É preciso desenvolver práticas que possibilitem que os alunos avancem no meio social, cultural e cognitivo. Como salienta Parente (2014): "poder-se-ia criar uma escola cuja preocupação central com os sujeitos educativos viesse a superar as imposições das padronizações e seriações promovidas nas escolas urbanas".

A Educação do Campo caminha para que seja vista e valorizada. Apesar de todas as dificuldades encontradas pelos professores, o estudo demonstra que, 
na medida em que se tem o apoio da comunidade, com a participação ativa, a transmissão de conhecimentos se torna relevante para os alunos, pois tais conhecimentos fazem parte do seu cotidiano. A integração da escola com a comunidade proporciona um novo olhar na prática pedagógica e fica evidente que o ensino-aprendizagem vai além dos livros, cartilhas e sala de aula.

\section{REFERÊNCIAS}

BRASIL, Diretrizes Curriculares da Rede Pública de Educação Básica do Estado do Paraná. Brasília: Secretaria de Estado da Educação, Curitiba, 2010.

\section{BRASIL. Secretaria de Educação Continuada, Alfabetização e}

Diversidade e Inclusão. Ministério da Educação. Escola da Terra. Brasília: SECAD/MEC, 2013.

BRITO, Mônica Cristina Cabello. Elaboração Participativa de uma agenda 21 da comunidade caiçara do Pouso da Cajaíba/ RJ. 2000. 150f. Dissertação (Mestrado em Ciências Florestais) Escola Superior de Agricultura Luiz de Queiroz, Universidade de São Paulo, Piracicaba, 2000.

CALDART, Roseli Salete. A Escola do Campo em Movimento. Revista Currículo sem Fronteiras, v. 3, n. 1, p. 60-81, jan./jun. 2003.

CALDART, Roseli Salete. Elementos para a construção de um projeto político e pedagógico da escola do campo. In: MOLINA, Monica Castagna; JESUS, Sônia Meire Santos Azevedo. Por uma Educação do Campo: contribuições para a construção de um projeto de Educação do Campo. Brasília, DF. 2004.

CALDART, Roseli Salete. Educação do campo: notas para um analise de percurso. In: MOLINA, M. Org. Educação do campo e pesquisa II: questões para reflexão. Brasília, DF: INCRA - MDA, 2010.

FONTANA, Maria Iolanda.; ROCHA, Luciane Pereira.; DAMBRAT, Ana Maria Santos. Investigação-ação na escola do Campo: formação e reestruturação do projeto político-pedagógico. In: SOUZA, Maria Antônia. Escola pública, educação do campo e projeto político-pedagógico. (Org.) Curitiba: UTP, 2018, p. 67-80.

Fórum Nacional de Educação do Campo - FONEC. Nota técnica sobre o Programa Escola Ativa. Brasília: [s.n.], 18 abr. 2011. Disponível em: <www.gepec.ufscar.br>. Acesso em: 12 nov. 2019.

LITTLE, W. Angela. Learning and Teaching in Multigrade Settings. Paper for Unesco EFA Global Monitoring Report 2005]. 2004. Disponível em: http://siteresources.worldbank.org/INTINDIA/43714321194542398355/21543 
231/ Learning and Teachingin Multi-Gradeclassrooms.pdf. Acesso em: 15 jan. 2020.

MARCONDES, Danilo. Iniciação à história da filosofia: dos Pré-socráticos a Wittgenstein. 12a. Ed. Brasil. Zahar, 2008.

MINAYO, Maria Cecília de Souza. O desafio do conhecimento científico: pesquisa qualitativa em saúde. 12a. Ed. São Paulo: Hucitec-Abrasco, 2010.

OLIVEIRA, Lia Maria Teixeira; CAMPOS, Marilia. Educação Básica do Campo. In: Dicionário do Campo. Rio de Janeiro; São Paulo: Escola Politécnica de Saúde Joaquim Venâncio, Expressão Popular, 2012, p. 239 -246.

PARENTE, Claúdia Mota Dário. Escolas Multisseriadas: a experiência internacional e reflexões para o caso brasileiro Ensaio: Avaliação e Políticas Públicas em Educação, vol. 22, núm. 82, enero-marzo, 2014, pp. 57-88 Fundação Cesgranrio Rio de Janeiro, Brasil.

PIANOVSKI, Regina Bonat. Ensino e aprendizagem em turmas multisseriadas. In: Escola pública, educação do campo e projeto-político-pedagógico. SOUZA, Maria Antônia de. A. (Org.). Curitiba: UTP, 2018.

SOUZA, Amílcar Maciel. Caminhos para uma educação ambiental voltada para a conservação dos mananciais de abastecimento público: um estudo de caso. 2005. 136f. Dissertação (Mestrado em Ciências Florestais), Universidade de São Paulo, Piracicaba, 2005.

TAFFAREL, Celi Neuza Zulke; JUNIOR, Claúdio Lira Santos. Pedagogia Histórico-Crítica e Formação de Docentes para a Escola do Campo. Educação \& Realidade, Porto Alegre, v. 41, n. 2, p. 429-452, abr./jun. 2016. Disponível em: http://dx.doi.org/10.1590/2175-623653917 Acesso em: 16 maio 2020.

UNESCO, Relatório de Monitoramento Global de EPT - Educação Para Todos - 2000-2015: Progressos e Desafios. Disponível em: Disponível em: https://unesdoc.unesco.org/ark:/48223/pf0000232565 Acesso em: 16 jan. 2020

VIGOTSKI, Lev Semionovitch. Psicologia pedagógica. São Paulo: Martins Fontes, 2010.

PRESTES, Zoia. Quando não é quase a mesma coisa: Análise de traduções de Lev Semionovitch Vigotski no Brasil. Repercussões no campo educacional. Universidade de Brasília. Faculdade de Educação. Programa de pós-graduação em Educação. Brasília, 2010. Disponível em: https://repositorio.unb.br/bitstream/10482/9123/1/2010_ZoiaRibeiroPrestes.p df Acesso em: 16 abr. 2020. 
Recebido em: 5 de abril de 2021.

Aceito em: 20 de maio de 2021. Publicado em: 15 de dezembro de 2021. 